\title{
Profitabilitas dan Solvabilitas Terhadap Nilai Perusahaan dengan Mediasi Harga Saham Perusahaan Farmasi di Indonesia
}

\section{Ahmad Idris}

Universitas Islam Kadiri, email : ahmadidris@uniska-kediri.ac.id

\section{ARTICLES}

INFORMATION

ABSTRACT

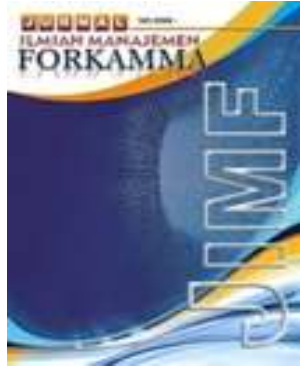

\section{JURNAL ILMIAH MANAJEMEN FORKAMMA}

\author{
Vol.4, No.2, Maret 2021 \\ Halaman : $134-147$ \\ (c) LPPM \& FORKAMMA
}

Prodi Magister Manajemen

UNVERSITAS PAMULANG

$$
\begin{array}{ll}
\text { ISSN (online) } & : 2599-171 X \\
\text { ISSN (print) } & : 2598-9545
\end{array}
$$

\section{Keyword :}

Profitabilitas; Solvabilitas; Nilai Perusahaan; Harga Saham

JEL. classification :

$\mathrm{O} 15$,

Contact Author :

\section{PRODI}

MAGISTER MANAJEMEN \& FORKAMMA UNPAM

JL.Surya Kencana No.1 Pamulang

Tangerang Selatan - Banten

Telp. (021) 7412566, Fax (021) 7412491 Email :

jurnalforkamma.unpam@gmail.com
Penelitian ini bertujuan untuk mengetahui pengaruh profitabilitas dan solvabilitas terhadap nilai perusahaan dengan harga saham sebagai variabel intervening pada industri farmasi di Bursa Efek Indonesia periode 2015-2019. Sampel industri farmasi sebanyak 6 perusahaan selama periode 2015-2019. Penelitian menggunakan analisis jalur. Profitabilitas menggunakan NPM, solvabilitas menggunakan DAR, harga saham menggunakan harga penutupan, dan nilai perusahaan menggunakan PBV. Analisis yang digunakan adalah analisis jalur. Hasil penelitian didapatkan bahwa NPM tidak berpengaruh signifikan terhadap harga saham, DAR tidak berpengaruh signifikan terhadap harga saham, NPM tidak berpengaruh signifikan terhadap PBV, DAR tidak berpengaruh signifikan terhadap PBV, harga saham berpengaruh signifikan terhadap PBV. Untuk variabel intervening diperoleh harga saham tidak dapat memediasi NPM terhadap PBV sedangkan harga saham mampu untuk memediasi DAR terhadap PBV.

This study aims to determine the effect of profitability and solvency on firm value with stock prices as an intervening variable in pharmaceutical companies listed on the Indonesia Stock Exchange for the period 2015-2019. Profitability is measured using NPM, solvency is measured using DAR, the stock price is measured using closing prices, and firm value is measured using PBV. The analysis technique used is path analysis. The results showed that NPM had no significant effect on stock prices, DAR had no significant effect on stock prices, NPM had no significant effect on PBV, DAR had no significant effect on PBV, stock prices had no significant effect on PBV. For the intervening variable, it is found that stock price cannot mediate NPM on PBV, and stock price can mediate DAR on $P B V$. 


\section{A. PENDAHULUAN}

Sektor farmasi merupakan sektor yang ada di bursa efek. Beberapa perusahaan farmasi skala nasional sudah mencatatkan sahamnya di BEl. Adapun tujuan didirikannya perusahaan farmasi ini selain mendapatkan keuntungan juga mempunyai tujuan membantu negara dalam memberikan fasilitas dan sarana kesehatan kepada masyarakat. Tentu ini merupakan tujuan yang bijaksana di tengah situasi dan kondisi kesehatan suatu bangsa yang tidak menentu. Dalam kondisi tidak menentu tersebut perusahaan farmasi diharapkan mampu meningkatkan laba yang dimilikinya demi kelangsungan perusahaan di masa datang. Perusahaan farmasi fokus menghasilkan produk kesehatan, layanan kesehatan, akses kesehatan bagi mitra bisnis, suplai bahan baku obat. Kegiatan operasional yang dilakukan perusahaan farmasi menjadi solusi kesehatan bagi masyarakat Indonesia.

Industri farmasi yang mencatatkan sahamnya ialah PT. Kimia Farma (Persero) Tbk mulai IPO bertepatan pada 4 Juli 2001 kode saham KAEF. Untuk PT. Kalbe Farma Tbk mulai IPO bertepatan pada 30 Juli 1991 dengan kode saham KLBF. Untuk PT. Darya Varia Laboratoria Tbk mulai IPO bertepatan pada 11 November 1994 dengan kode saham DVLA. Untuk PT. Merck Tbk mulai IPO bertepatan pada 23 Juli 1981 dengan kode saham MERK. Untuk PT. Tempo Scan Pasific Tbk mulai IPO bertepatan pada 17 Juni 1994 dengan kode saham TSPC. Untuk PT. Industri Jamu \& Farmasi Sido Muncul Tbk mulai IPO bertepatan 18 Desember 2013 kode saham SIDO.

Industri farmasi yang terdapat di Indonesia pasti mengalami berbagai macam tantangan dan perbaikan terus menerus agar senantiasa eksis dalam dunia bisnis khususnya sektor farmasi. Peningkatan kinerja terus dilakukan demi mendapatkan daya saing berkelanjutan dan pertumbuhan usaha yang berkelanjutan. Perbaikan terus menerus merupakan salah satu kiat agar dapat memberikan produk kesehatan dan layanan kesehatan yang bermutu agar perusahaan farmasi tetap eksis. Salah satu contoh terjadinya tantangan seperti yang dialami Kimia Farma tahun 2019 mengakuisisi Phapros, yang tentunya ini menjadi daya saing demi pertumbuhan usaha Kimia Farma. Ketidakpastian ekonomi global dan kondisi politik negara Indonesia turut andil mempengaruhi kinerja perusahaan farmasi, sehingga perlu terus-menerus melakukan kajian-kajian berkaitan kinerja keuangan.

Perusahaan farmasi perlu melakukan penilaian kinerja agar pemegang saham mengetahui perusahaan tersebut berada pada kondisi yang bagus atau tidak. Pemilihan rasio keuangan merupakan cara tepat mengetahui kinerja keuangan. Salah satu cara yang diharapkan mampu melihat kinerja keuangan tersebut adalah menghitung rasio profitabilitas. Dengan rasio profitabilitas melihat sejauhmana perusahaan-perusahaan farmasi menghasilkan laba dari penjualan produk kesehatan, perolehan aktiva pabrik, dan modal perusahaan farmasi yang ada. Diharapkan meningkatnya profitabilitas dari perusahaan farmasi dapat menaikkan nilai perusahaan farmasi tersebut. Beberapa kajian terdahulu mengenai profitabilitas dilakukan oleh Ananda (2017), Husaini (2012, dan Rinati (2012). Sedangkan kajian mengenai solvabilitas dilakukan oleh Pamungkas (2017), Manoppo (2017), dan Nur'aidawati (2018). Sedangkan kajian mengenai harga saham dan nilai perusahaan dilakukan oleh Mentari (2015), Ogolmagai (2013), Ponggohong (2016), Prasetyorini (2013), Rudangga (2016), Saputra (2019), dan Sia (2011). Sehingga penelitian ini perlu dilakukan untuk membandingkan dan melengkapi penelitian-penelitian sebelumnya.

Profitabilitas dianggap mampu mempengaruhi nilai perusahaan. Menurut Prasetyorini (2013:194) naiknya profitabilitas akan menaikkan laba per lembar saham di pasar modal. Aksi investor menanamkan modal dengan melaksanakan pembelian saham sesudah mengamati peningkatan laba pada industri farmasi. Nilai perusahaan di pasar 
modal bakal bertambah bersamaan meningkatnya jumlah investor yang melaksanakan pembelian saham pada industri yang menjadikan harga saham farmasi akan turut naik.

Rasio yang diperhatikan selain profitabilitas perusahaan adalah rasio solvabilitas yang dimiliki perusahaan. Solvabilitas merupakan sebuah tanggung jawab dari perusahaan dalam membayar seluruh utang-utangnya. Apabila perusahaan dilikuidasi maka wajib melunasi utang jangka pendek dan utang jangka panjang. Perolehan aktiva secara tidak tunai dengan cara utang akan menambah rasio solvabilitas. Dengan kata lain perbandingan total utang dengan total aktiva yang ada. Jika total utang lebih banyak dari total aktiva maka nilai rasio solvabilitas ikut tinggi. Penting bagi perusahaan untuk menjaga tingkat solvabilitas perusahaan karena solvabilitas yang tinggi berpengaruh buruk bagi kondisi kesehatan perusahaan karena menumpuknya hutang yang dimiliki perusahaan. Hal ini dikemukan oleh Rudangga \& Sudiarta (2016: 4399) bahwa perusahaan yang terlalu sering melakukan pembelian aktiva dengan melalui mekanisme hutang, dianggap perusahaan yang tidak sehat, dikarenakan kondisi ini bisa menurunkan laba perusahaan. Karena fluktuasi tingkat hutang berpengaruh terhadap penilaian investor di pasar modal.

Nilai perusahaan berhubungan dengan fluktuasi harga saham setiap hari yang menggambarkan persepsi investor secara kesuluruhan atas perusahaan tersebut. Saham memperlihatkan permintaan dan penawaran seluruh pelaku pasar secara komprehensif, harga saham menjadi salah satu parameter dari kinerja manajemen sebuah perusahaan (Rudangga \& Sudiarta, 2016: 4396). Nilai perusahaan menciptakan nilai positif bagi pemegang saham. Sehingga perusahaan farmasi yang ada di Indonesia dapat menghadapi tingkat persaingan bisnis yang semakin ketat apalagi investor lebih selektif dalam memilih perusahaan untuk menanamkan modalnya. Hasil penelitian Saputra \& Martha (2019) bahwa nilai perusahaan memberikan pengaruh pada saham dengan hasil peningkatan nilai perusahaan akan meningkatkan harga saham dan tentunya juga memberi harapan bagi investor dan menggambarkan manajemen berhasil dalam mengelola perusahaan farmasi.

Saham merupakan bukti kepemilikan dari sebuah perusahaan. Saham digolongkan menjadi 2 macam yaitu pertama saham preferen dan kedua saham biasa. Saham yang menghasilkan dividen dengan jumlah tetap dan ditentukan sebelumnya disebut saham preferen. Saham yang besaran dividennya tidak tetap dan tidak tetap jumlah serta tanpa kewajiban membagikan dividen setiap tahunnya meskipun perusahaan mendapatkan laba tahun disebut saham biasa. Menurut Saputra \& Martha (2019) semakin besar kepemilikan saham di sebuah perusahaan menunjukkan semakin besar kekuasaannya di perusahaan tersebut.

Berdasarkan penjelasan tersebut dibuat rumusan masalah yang dilakukan:

1. Apakah Profitabilitas (NPM) mempengaruhi Harga Saham?

2. Apakah Solvabilitas (DAR) mempengaruhi Harga Saham?

3. Apakah Profitabilitas (NPM) mempengaruhi Nilai Perusahaan (PBV)?

4. Apakah Solvabilitas (DAR) mempengaruhi Nilai Perusahaan (PBV)?

5. Apakah Harga Saham mempengaruhi Nilai Perusahaan (PBV)?

6. Apakah Harga Saham memediasi Profitabilitas (NPM) terhadap Nilai Perusahaan (PBV)?

7. Apakah Harga Saham memediasi Solvabilitas (DAR) terhadap Nilai Perusahaan (PBV)?

Perusahaan perlu mengambil kebijakan untuk membangun kepercayaan investor, kreditor, dan pasar untuk melindungi keberlanjutan bisnis perusahaan farmasi. Melihat semakin ketatnya persaingan di bursa efek yang menyebabkan setiap perusahaan berupaya untuk meningkatkan harga saham maka tujuan penelitian yang hendak diperoleh yaitu mengetahui apakah harga saham bisa memediasi profitabilitas dan solvabilitas terhadap nilai perusahaan farmasi tahun 2015-2019. 


\section{B. KAJIAN LITERATUR}

\section{Profitabilitas}

Penelitian ini mengambil rasio profitabilitas dalam melihat kinerja perusahaan farmasi memperoleh laba. Rasio yang dilihat sesuai dengan penelitian ini adalah NPM (Net Profit Margin). Menurut Harahap (2010: 304) dalam Manoppo et al. (2017: 1815) menjelaskan NPM (Net Profit Margin) yang disebut margin laba bersih dihitung dalam rangka menilai seberapa besar persentase laba bersih dengan penjualan bersih perusahaan. Hal senada juga diungkapkan Syamsuddin (2007: 62) dalam Husaini (2012: 46) bahwa NPM adalah rasio perbandingan nilai dari laba bersih sesudah pajak dengan nilai penjualan. Apabila NPM terus tinggi menggambarkan efisiensi yang laba bersih terhadap penjualan sangat tinggi. Menurut (Rinati, 2012) NPM yang tinggi menjelaskan perusahaan produktif menghasilkan laba.

\section{Solvabilitas}

Rasio solvabilitas dihitung menggunakan Debt To Asset Ratio (DAR). Dewi et. Al (2014) dalam Pamungkas \& Maryati (2017: 413) mengemukakan rasio keuangan yang memberikan informasi apakah perusahaan memilih pembiayaan dengan utang dalam perolehan jumlah aktiva atau aset. Menurut Hovakimian et al. (2001: 1) bahwa untuk menutupi utang perusahaan cenderung menggunakan laba. Namun, terkadang pimpinan perusahaan lebih suka memperoleh aset yang dimiliki menggunakan laba dibandingkan hutang tetapi beberapa perusahaan melakukan sebaliknya. Dari definisi di atas disimpulkan semakin tinggi DAR meningkatkan risiko kerugian yang dialami perusahaan dikarenakan perusahaan memiliki kewajiban melunasi utang yang sangat tinggi.

\section{Nilai Perusahaan}

Kerjasama manajemen perusahaan dan pemilik diduga meningkatkan nilai perusahaan pada industri farmasi. Pengukuran nilai perusahaan industri farmasi memakai PBV (Price to Book Value). Menurut Ananda (2017: 26) nilai perusahaan dapat dijadikan dasar persepsi investor atas harga saham perusahaan tersebut. Menurut Rahayu \& Sari (2018: 73) bahwa nilai perusahaan merupakan keadaan perusahaan atas kinerja saham. Dari definisi di atas disimpulkan tingginya nilai perusahaan dilihat dari tingginya harga saham industri farmasi.

\section{Harga Saham}

Bentuk saham merupakan dokumen yang menjelaskan kepemilikan modal perusahaan. Kepemilikan perusahaan ditetapkan oleh besarnya penyertaan modal yang ditanam di perusahaan tersebut (Darmadji \& Fakhruddin, 2001). Sia \& Tjun (2011:140) mengatakan bahwa harga saham di bursa efek setiap hari berfluktuasi sesuai pengaruh dari faktor di dalam dan faktor di luar perusahaan. Faktor di dalam berupa pengumuman laba perusahaan, pengumuman akan pembagian dividen, penilaian kinerja perusahaan secara periode, pergantian dari pengurus perusahaan, dan informasi lainnya yang berhubungan operasi dari perusahaan. Sedangkan faktor luar perusahaan berupa isu-isu kondisi politik, perkembangan perusahaan pesaing, situasi dari keamanan negara, perubahan kurs, tingkat suku bunga, inflasi, dan informasi lainnya di luar perusahaan. Faktor luar yang berdampak terhadap harga saham adalah kondisi perekonomian dunia contohnya adanya perang dagang Amerika Serikat dengan Tiongkok menjadikan jatuhnya harga komoditas dunia sehingga menjadikan perlambatan ekonomi global. 


\section{Hipotesis Penelitian}

$\mathrm{Ha}_{1}$ : Profitabilitas (NPM) berpengaruh terhadap Harga Saham

$\mathrm{Ha}_{2}$ : Solvabilitas (DAR) berpengaruh terhadap Harga Saham

$\mathrm{Ha}_{3}$ : Profitabilitas (NPM) berpengaruh terhadap Nilai Perusahaan (PBV)

$\mathrm{Ha}_{4}$ : Solvabilitas (DAR) berpengaruh terhadap Nilai Perusahaan (PBV)

$\mathrm{Ha}_{5}$ : Harga Saham berpengaruh terhadap Nilai Perusahaan (PBV)

$\mathrm{Ha}_{6}$ : Harga Saham mampu memediasi pengaruh Profitabilitas terhadap Nilai Perusahaan (PBV)

$\mathrm{Ha}_{7}$ : Harga Saham mampu memediasi pengaruh Solvabilitas terhadap Nilai Perusahaan (PBV)

\section{Kerangka Berpikir}

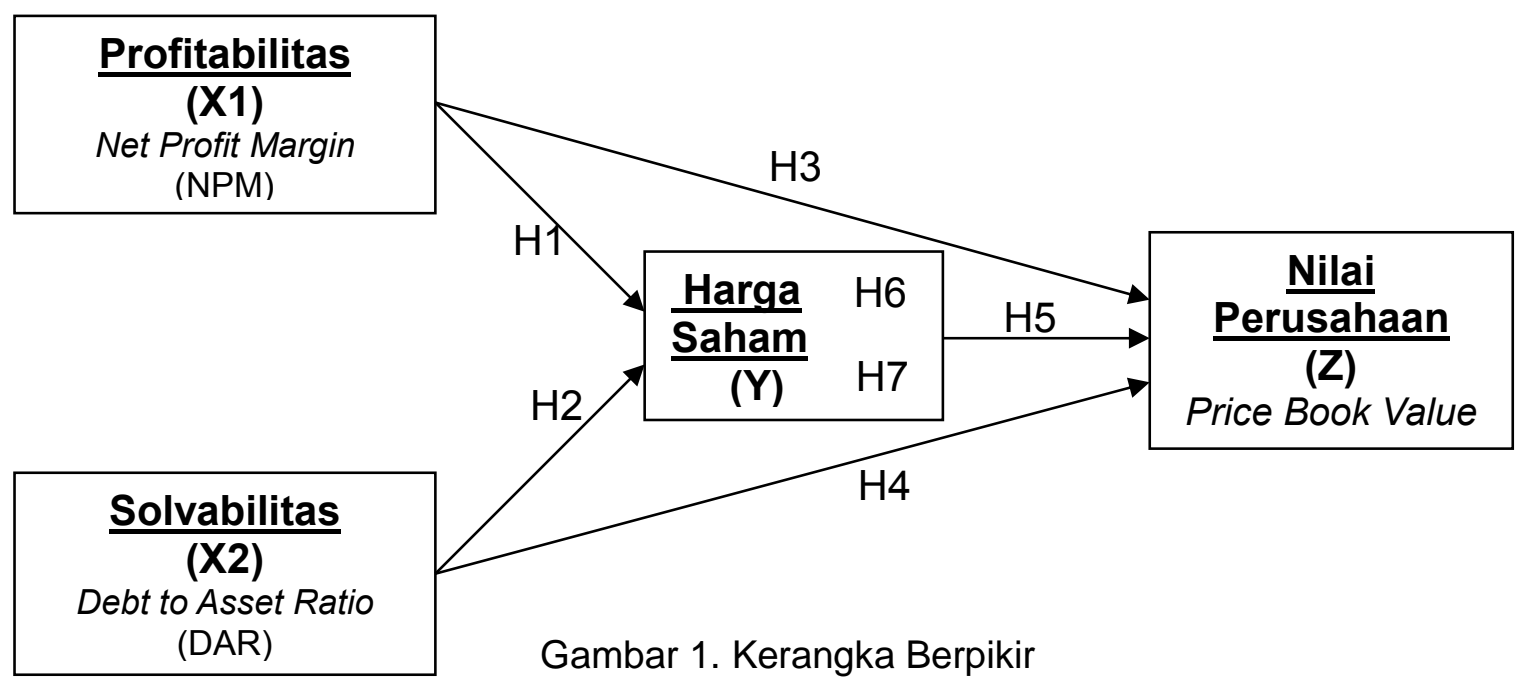

\section{METODOLOGI PENELITIAN}

Jenis penelitian asosiatif kausal digunakan dalam penelitian ini yaitu ingin mengetahui pengaruh antara variabel. Dengan menggunakan asumsi pendekatan kuantitatif. Sumber data adalah laporan keuangan yang diumumkan kepada publik. Populasinya adalah industri farmasi yang sahamnya tercatat di BEI pada 2015-2019.

Dari jenis penelitian dan sumber data di atas, maka peneliti mengambil data dari laman resmi perusahaan dan bursa efek. Analisis jalur yang merupakan pengembangan bentuk regresi yang mampu melihat hubungan yang dibentuk variabel independen/bebas dengan variabel dependen/terikat melalui variabel intervening/perantara.

Pengambilan sampel yang dipakai adalah teknik purposive sampling artinya pengambilan sampling menggunakan kriteria tertentu. Adapun beberapa kriteria yang dipakai sebagai berikut:

1. Industri farmasi yang mencatatkan sahamnya di Bursa Efek Indonesia (BEI).

2. Industri farmasi yang membukukan laba bersih positif.

3. Industri farmasi yang memberikan laporan keuangan secara komprehensif dalam kurun waktu 2015-2019 sesuai variabel penelitian. 
Tabel 1. Sampel Penelitian

\begin{tabular}{lllccccc}
\hline No & Kode & Nama & 2015 & 2016 & 2017 & 2018 & 2019 \\
\hline 1. & DVLA & PT. Darya Varia Laboratoria Tbk & $\sqrt{ }$ & $\sqrt{ }$ & $\sqrt{ }$ & $\sqrt{ }$ & $\sqrt{ }$ \\
2. & KAEF & PT. Kimia Farma (Persero) Tbk & $\sqrt{ }$ & $\sqrt{ }$ & $\sqrt{ }$ & $\sqrt{ }$ & $\sqrt{ }$ \\
3. & KLBF & PT. Kalbe Farma Tbk & $\sqrt{ }$ & $\sqrt{ }$ & $\sqrt{ }$ & $\sqrt{ }$ & $\sqrt{ }$ \\
4. & MERK & PT. Merck Tbk & $\sqrt{ }$ & $\sqrt{ }$ & $\sqrt{ }$ & $\sqrt{ }$ & $\sqrt{ }$ \\
5. & TSPC & PT. Tempo Scan Pasific Tbk & $\sqrt{ }$ & $\sqrt{ }$ & $\sqrt{ }$ & $\sqrt{ }$ & $\sqrt{ }$ \\
6. & SIDO & PT. Industri Jamu dan Farmasi & $\sqrt{ }$ & $\sqrt{ }$ & $\sqrt{ }$ & $\sqrt{ }$ & $\sqrt{ }$ \\
& & \multicolumn{7}{c}{ Sido Muncul Tbk Laporan Keuangan } \\
\hline
\end{tabular}

Sumber : www.idx.co.id, 2021

Penetapan kriteria di atas maka didapatkan 6 perusahaan yang layak untuk diambil data laporan keuangannya selama periode 2015-2019 sehingga jumlah sampel berdasarkan jumlah laporan keuangan sebanyak 30 data seperti pada tabel 1 . Variabel bebas $(X)$ yaitu NPM, DAR, dan variabel mediasi $(Y)$ yaitu harga saham, serta variabel terikat PBV.

\section{Definisi Operasional Variabel}

Tabel 2. Pengukuran Variabel

\begin{tabular}{cccc}
\hline No & Variabel & Pengukuran & Literatur \\
\hline 1. & Profitabilitas (X1) & NPM $=\frac{\text { EAT }}{\text { Sales }} \times 100 \%$ & (Atmaja, 2008) \\
\hline 2. & Solvabilitas (X2) & DAR $=\frac{\text { Total Debt }}{\text { Total Asset }} \times 100 \%$ & (Kasmir, 2014: 156) \\
\hline 3. & Harga Saham (Y) & Harga Penutupan & (Nur'aidawati, 2018: \\
\hline 4. & Nilai Perusahaan & PBV & Market Price per Share \\
& $(\mathrm{Z})$ & Book Value per Share & (Fakhruddin; \\
& & &
\end{tabular}

Sumber : Peneliti, 2021

Berdasarkan hipotesis yang ada maka dibuat 2 (dua) buah persamaan:

\section{Persamaan sub struktural 1}

$\mathrm{Y}=\rho_{\mathrm{yx} 1} \mathrm{X} 1+\rho_{\mathrm{yx} 2} \mathrm{X} 2$

Harga Saham $=\rho_{\mathrm{yx} 1} \mathrm{NPM}+\rho_{\mathrm{yx} 2} \mathrm{DAR}$

\section{Persamaan sub struktural 2}

$\mathrm{Z}=\rho_{\mathrm{zx} 1} \mathrm{X} 1+\rho_{\mathrm{zx} 2} \mathrm{X} 2+\rho_{\mathrm{zy}} \mathrm{Y}$

$\mathrm{PBV}=\rho_{\mathrm{zx} 1} \mathrm{NPM}+\rho_{\mathrm{zx} 2}$ Solvabilitas $+\rho_{\mathrm{zy}}$ Harga Saham

\section{HASIL DAN PEMBAHASAN}

\section{Analisis Deskriptif}

Nilai PBV terendah sebesar 0,94 yang diperoleh KAEF tahun 2019, untuk PBV tertinggi yaitu 6,41 diperoleh MERK tahun 2015. Dari data di atas rata-rata PBV dari 6 
(enam) perusahaan periode 2015-2019 sebesar 3,25. Ada 3 (tiga) perusahaan periode 2015-2019 memperoleh rata-rata PBV di atas rata-rata PBV total yaitu KAEF, KLBF, dan MERK sedangkan 3 (tiga) lainnya berada di bawah rata-rata PBV total yatu DVLA, TSPC, dan SIDO.

Tabel 3. PBV (Price to Book Value)

\begin{tabular}{ccccccccc}
\hline No & Kode & $\mathbf{2 0 1 5}$ & $\mathbf{2 0 1 6}$ & $\mathbf{2 0 1 7}$ & $\mathbf{2 0 1 8}$ & $\mathbf{2 0 1 9}$ & Jumlah & Rata2 \\
\hline 1 & DVLA & 1,50 & 1,82 & 1,97 & 1,81 & 1,93 & 9,03 & 1,81 \\
2 & KAEF & 2,35 & 6,72 & 5,83 & 4,30 & 0,94 & 20,14 & 4,03 \\
3 & KLBF & 5,66 & 5,70 & 5,70 & 4,66 & 4,55 & 26,27 & 5,25 \\
4 & MERK & 6,41 & 7,07 & 6,19 & 3,72 & 1,42 & 24,81 & 4,96 \\
5 & TSPC & 1,82 & 1,91 & 1,59 & 1,15 & 1,08 & 7,55 & 1,51 \\
6 & SIDO & 1,59 & 1,41 & 1,41 & 2,17 & 3,12 & 9,7 & 1,94 \\
\hline \multicolumn{2}{r}{ Rata-Rata } & 3,22 & 4,11 & 3,78 & 2,97 & 2,17 & 16,25 & 3,25 \\
\hline
\end{tabular}

Sumber : www.idx.co.id, 2020

Tabel 4. Harga Saham

\begin{tabular}{ccccccc}
\hline No & Kode & $\mathbf{2 0 1 5}$ & $\mathbf{2 0 1 6}$ & $\mathbf{2 0 1 7}$ & $\mathbf{2 0 1 8}$ & $\mathbf{2 0 1 9}$ \\
\hline 1 & DVLA & 1.300 & 1.755 & 1.960 & 1.940 & 2.250 \\
2 & KAEF & 870 & 2.750 & 2.700 & 2.600 & 1.250 \\
3 & KLBF & 1.320 & 1.515 & 1.690 & 1.520 & 1.620 \\
4 & MERK & 6.775 & 9.200 & 8.500 & 4.300 & 2.850 \\
5 & TSPC & 1.750 & 1.970 & 1.800 & 1.390 & 1.395 \\
6 & SIDO & 275 & 260 & 273 & 420 & 638 \\
\hline
\end{tabular}

Sumber : www.idx.co.id, 2020

Tabel 4 memperlihatkan harga saham industri farmasi 2015-2019 yang diambil dari harga saham penutupan akhir tahun. Harga terendah Rp. 260 diperoleh oleh SIDO tahun 2016, dan harga saham tertinggi Rp. 9.200 pada MERK di tahun 2016.

Tabel 5. NPM (Net Profit Margin)

\begin{tabular}{ccccccccc}
\hline No & Kode & $\mathbf{2 0 1 5}$ & $\mathbf{2 0 1 6}$ & $\mathbf{2 0 1 7}$ & $\mathbf{2 0 1 8}$ & $\mathbf{2 0 1 9}$ & Jumlah & Rata2 \\
\hline 1 & DVLA & 8,26 & 10,48 & 10,30 & 11,81 & 12,23 & 53,08 & 10,62 \\
2 & KAEF & 5,46 & 4,67 & 5,41 & 5,39 & 0,17 & 21,1 & 4,22 \\
3 & KLBF & 11,50 & 12,13 & 12,16 & 16,15 & 11,21 & 63,15 & 12,63 \\
4 & MERK & 14,49 & 14,87 & 12,51 & 6,11 & 10,51 & 58,49 & 11,70 \\
5 & TSPC & 6,47 & 5,97 & 5,83 & 5,36 & 5,41 & 29,04 & 5,81 \\
\hline 6 & SIDO & 19,72 & 17,76 & 20,74 & 24,02 & 26,33 & 108,57 & 21,71 \\
\hline Rata-Rata & 10,98 & 10,98 & 11,16 & 11,47 & 10,98 & 55,57 & 11,11 \\
\hline
\end{tabular}

Sumber : www.idx.co.id, 2020

Didapatkan nilai NPM terendah 0,17 pada KAEF tahun 2019, dan NPM tertinggi 26,33 diperoleh SIDO tahun 2019. Dari data di atas diketahui rata-rata NPM dari 6 (enam) perusahaan periode 2015-2019 sebesar 11,11. Ada 3 (tiga) perusahaan periode 20152019 mempunyai rata-rata NPM berada di atas rata-rata NPM total yaitu DVLA, KAEF, dan TSPC sedangkan 3 (tiga) yang lain berada di bawah rata-rata NPM total yatu KLBF, MERK, dan SIDO.

Tabel 6. DAR (Debt to Asset Ratio)

\begin{tabular}{ccccccccc}
\hline No & Kode & $\mathbf{2 0 1 5}$ & $\mathbf{2 0 1 6}$ & $\mathbf{2 0 1 7}$ & $\mathbf{2 0 1 8}$ & $\mathbf{2 0 1 9}$ & Jumlah & Rata2 \\
\hline 1 & DVLA & 29,26 & 29,50 & 31,97 & 28,68 & 28,63 & 148,04 & 29,61 \\
2 & KAEF & 40,13 & 50,76 & 57,80 & 64,52 & 59,61 & 272,82 & 54,56 \\
3 & KLBF & 20,14 & 18,14 & 16,38 & 15,71 & 17,56 & 87,93 & 17,59 \\
4 & MERK & 26,20 & 21,68 & 27,34 & 58,97 & 34,08 & 168,27 & 33,65 \\
5 & TSPC & 30,99 & 29,62 & 31,65 & 30,97 & 30,83 & 154,06 & 30,81
\end{tabular}




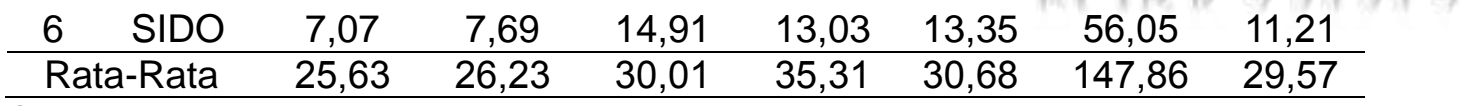

Sumber : www.idx.co.id, 2020

Didapatkan nilai DAR terendah sebesar 7,07 yang diperoleh SIDO pada tahun 2015, dan nilai DAR tertinggi sebesar 64,52 yang diperoleh KAEF pada tahun 2018. Dari data di atas diketahui rata-rata DAR dari 6 (enam) perusahaan periode 2015-2019 sebesar 29,57. Ada 4 (empat) perusahaan periode 2015-2019 nilai rata-rata DAR di atas rata-rata DAR total yaitu DVLA, KAEF, MERK, dan TSPC sedangkan 2 (dua) yang lain nilai rata-rata berada di bawah rata-rata DAR total yatu KLBF dan SIDO.

\section{Uji Normalitas}

Untuk memperlihatkan data penelitian berdistribusi normal menggunakan uji kolmogorov smirnov. Data NPM, DAR, Harga Saham, dan PBV perusahaan farmasi berdistribusi normal dibuktikan Asymp. Sig. (2-tailed) $0.072>0.05$. Penelitian dilanjutkan ke tahapan analisis berikutnya.

Tabel 7. Uji Normalitas

\begin{tabular}{cc}
\hline Item & $\begin{array}{c}\text { Nilai Unstandardized } \\
\text { Residual }\end{array}$ \\
\hline $\mathrm{N}$ & 30 \\
\hline Kolmogorov-Smirnov Z & 1.290 \\
\hline Asymp. Sig. (2-tailed) & .072 \\
\hline Sumber : Data diolah, 2021 &
\end{tabular}

\section{Uji Multikolinearitas}

Untuk mengetahui tidak ada hubungan yang kuat antara NPM dan DAR. Didapatkan VIF $<10$ artinya data penelitian NPM, DAR, Harga Saham, dan PBV perusahaan farmasi yang diteliti tidak terjadi gejala multikolinearitas.

Tabel 8. Uji Multikolinearitas

\begin{tabular}{|c|c|}
\hline Variabel & VIF \\
\hline NPM & 2.586 \\
\hline DAR & 2.658 \\
\hline SAHAM & 1.045 \\
\hline
\end{tabular}

\section{Uji Heteroskedastisitas}

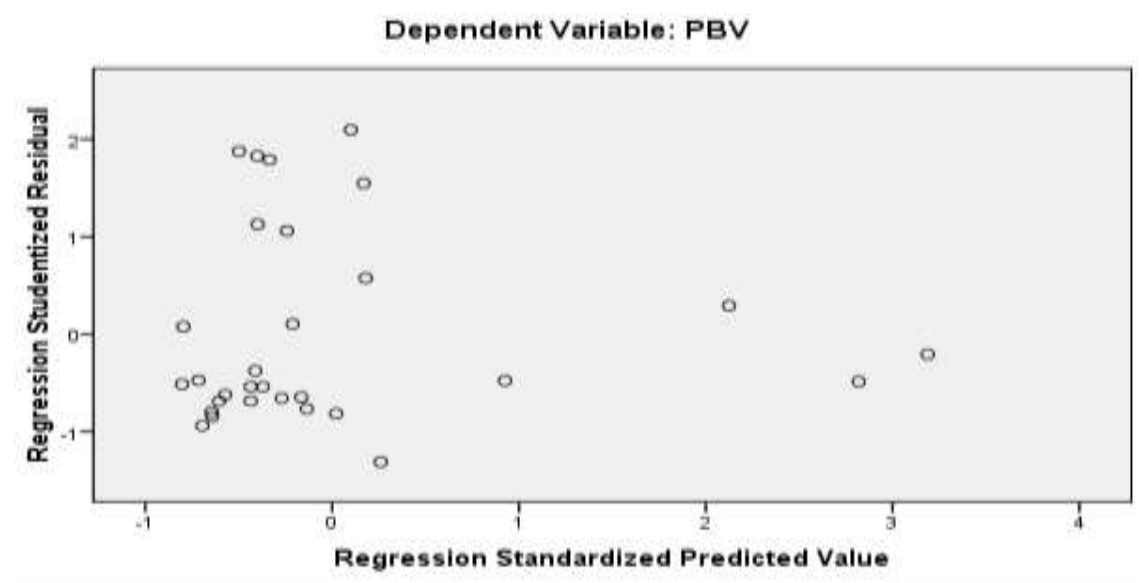

Gambar 2. Scatter Plot 
Pada gambar 2 didapatkan plot menyebar acak. Dengan gambar scatter plot tersebut data NPM, DAR, Harga Saham, dan PBV perusahaan farmasi diasumsikan bebas gejala heteroskedastisitas.

\section{Uji Autokorelasi}

Berdasarkan uji autokorelasi didapatkan Durbin Watson (DW) 1.818. Kemudian DW dibandingkan dengan $\mathrm{dL}=1.213$ dan $\mathrm{dU}=1.649$ pada tabel durbin watson dengan $\mathrm{k}=3$ $\mathrm{n}=30$. Dengan kriteria $\mathrm{dU} \leq \mathrm{dW} \leq 4-\mathrm{dU}$, maka ditulis perbandingan $1.649 \leq 1.818 \leq 2.350$. Didapatkan data penelitian NPM, DAR, Harga Saham, dan PBV tidak terjadi autokorelasi.

Tabel 9. Uji Autokorelasi

Durbin-Watson 1.818

Sumber : Data diolah, 2021

\section{Analisis Jalur (Path Analysis) Persamaan Sub Struktural 1}

Tabel 10. Hasil Persamaan Sub Struktural 1

\begin{tabular}{lccc}
\hline Variabel & Beta & T & Sig. \\
\hline NPM & .253 & .893 & .380 \\
DAR & .202 & .713 & .482 \\
\hline
\end{tabular}

Sumber : Data diolah, 2021

Persamaan sub struktural 1 menjadi SAHAM $=0.253 \mathrm{NPM}+0.202 \mathrm{DAR}$. Didapat pengaruh langsung NPM kepada Harga Saham industri farmasi 0.253 dengan Sig. 0.380 menjelaskan variabel NPM tidak berpengaruh signifikan kepada Harga Saham. Pengaruh langsung variabel DAR sebesar 0.202 dengan Sig. 0.482 menjelaskan variabel DAR tidak berpengaruh kepada Harga Saham industri farmasi.

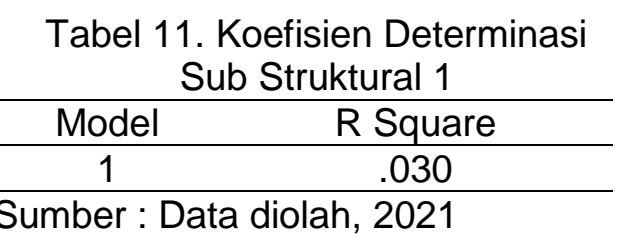

Pada persamaan sub struktural 1 didapat $R$ Square sebesar 0.030 menjelaskan prosentase seumbangan pengaruh NPM dan DAR kepada Harga Saham sebesar 3\%. Sementara untuk e1 $=\sqrt{ }(1-0,030)=0,985$.

\section{Persamaan Sub Struktural 2}

Persamaan sub struktural 2 diambil dari kolom Beta, sehingga persamaannya menjadi $\mathrm{PBV}=0.186 \mathrm{NPM}-0.075 \mathrm{DAR}+0.544 \mathrm{SAHAM}$. Pengaruh langsung NPM terhadap PBV yaitu 0.186 dengan Sig. 0.435 artinya NPM tidak berpengaruh signifikan kepada variabel PBV. Pengaruh langsung DAR terhadap PBV yaitu -0.075 dengan Sig. 0.750 menjelaskan variabel DAR tidak mempunyai pengaruh signifikan kepada PBV. Pengaruh langsung Harga Saham kepada PBV yaitu 0.544 dengan Sig. 0.002 menjelaskan Harga Saham mempunyai pengaruh signifikan terhadap PBV pada industri farmasi. 
Tabel 12. Hasil Persamaan Sub Struktural 2

\begin{tabular}{lccc}
\hline \multicolumn{1}{c}{ Variabel } & Beta & $\mathrm{t}$ & Sig. \\
\hline NPM & .186 & .793 & .435 \\
DAR & -.075 & -.322 & .750 \\
SAHAM & .544 & 3.390 & .002 \\
\hline
\end{tabular}

Sumber : Data diolah, 2021

Tabel 13. Koefisien Determinasi

Persamaan Sub Struktural 2

\begin{tabular}{cc}
\hline Model & R Square \\
\hline 1 & .376 \\
\hline
\end{tabular}

Sumber : Data diolah, 2021

Persamaan sub struktural 2 mendapatkan koefisien determinasi (R Square) yaitu 0.376 menjelaskan prosentase sumbangan pengaruh NPM, DAR, dan SAHAM terhadap PBV sebesar $37,6 \%$ dan sisanya $62,4 \%$ adalah prosentase kontribusi variabel lain. Sementara untuk e2 $=\sqrt{ }(1-0,376)=0,789$.

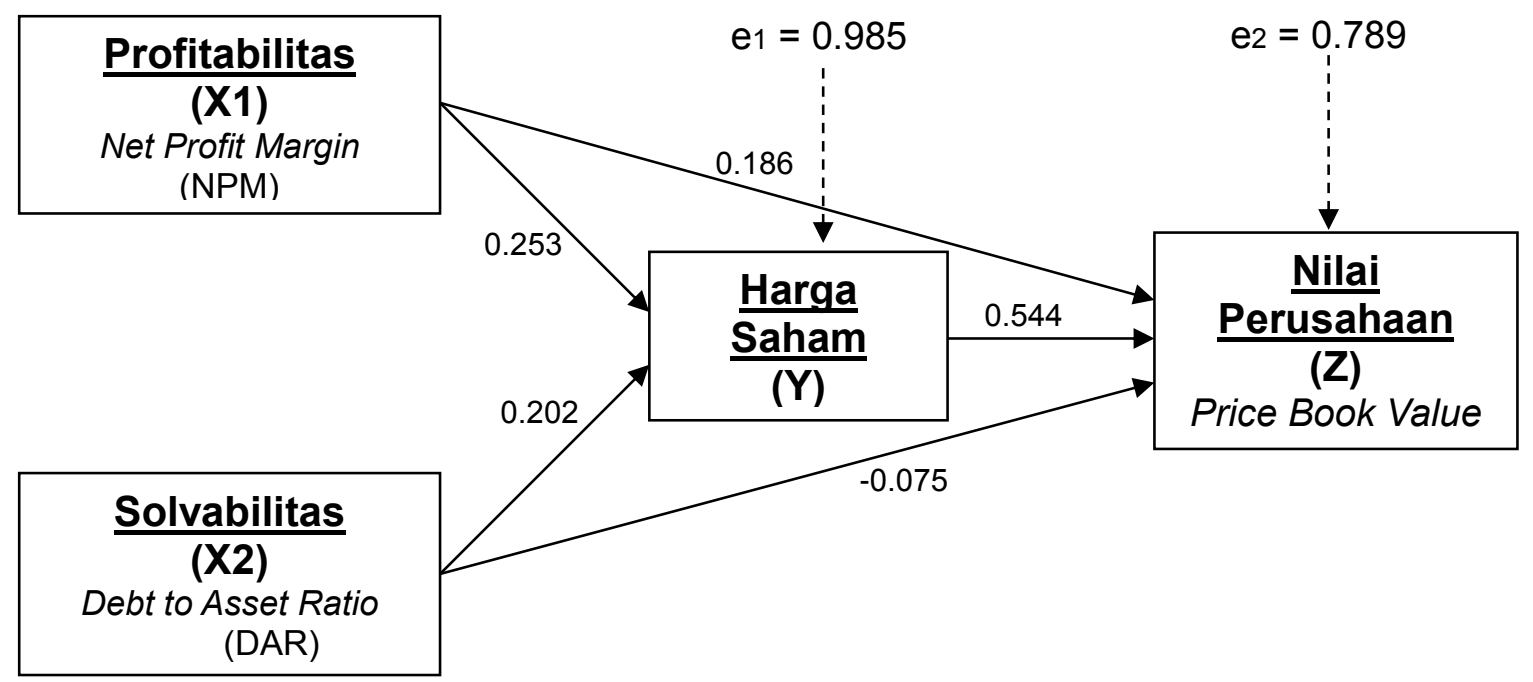

Gambar 3. Diagram Analisis Jalur

Pengaruh tidak langsung NPM terhadap PBV melalui Harga Saham sebesar koefisien jalur $=0.253 \times 0.544=0.138$. Koefisien jalur $0.138<0.186$ artinya Harga Saham tidak mampu memediasi pengaruh NPM terhadap PBV. Pengaruh tidak langsung DAR terhadap PBV sebesar koefisien jalur $=0.202 \times 0.544=0.109$. Koefisien jalur 0.109 $>-0.075$ artinya Harga Saham mampu memediasi pengaruh DAR terhadap PBV. Maka dapat dibuatkan diagram jalur seperti gambar 3 di bawah ini.

$\mathrm{Ha}_{1}$ : Profitabilitas memiliki pengaruh terhadap Harga Saham

Persamaan sub struktural 1 menunjukkan t hitung 0.893 Signifikansi $(0.380>0.05)$. Variabel NPM tidak berpengaruh signiifikan kepada variabel Harga Saham pada industri farmasi. Menjelaskan semakin tinggi NPM belum mampu memprediksi kenaikan Harga Saham, akan tetapi bukan berarti profit yang didapatkan perusahaan farmasi tidak mempunyai pengaruh kepada Harga Saham karena bisa saja investor tidak hanya melihat tingkat keuntungan yang dimiliki perusahaan tetapi melihat faktor lain dalam kinerja keuangan perusahaan seperti tingkat penjualan, kebijakan deviden, dsb. Hal ini relevan 
dengan penelitian Rinati (2012: 9) dan Mentari (2015: 13) .Berdasarkan penjelasan tersebut maka $\mathrm{Ha}_{1}$ ditolak.

$\mathrm{Ha}_{2}$ : Solvabilitas memiliki pengaruh terhadap Harga Saham

Berdasarkan hasil output persamaan sub struktural 1, diperoleh t hitung $0.713 \mathrm{Sig}$. $0.482>0.05$. DAR tidak berpengaruh signifikan kepada Harga Saham industri Farmasi. Menjelaskan DAR industri farmasi belum mampu menarik minat investor untuk memiliki saham pada perusahaan farmasi. Kondisi ini relevan dengan apa yang diteliti Ponggohong (2016: 893) dan Vasta (2013). Berdasarkan penjelasan tersebut maka $\mathrm{Ha}_{2}$ ditolak.

$\mathrm{Ha}_{3}$ : Profitabilitas memiliki pengaruh terhadap Nilai Perusahaan

Dari output persamaan sub struktural 2, diperoleh t hitung 0.793 dan Sig. $0.435>$ 0.05. NPM tidak berpengaruh signifikan kepada PBV. Menjelaskan bahwa variabel NPM belum mampu meningkatkan variabel PBV, akan tetapi perusahaan diharapkan terus memperbaiki nilai NPM karena akan berdampak meningkatkan kinerja keuangan dengan tujuan meningkatkan persepsi investor atas nilai perusahaan farmasi. Hal ini relevan dengan penelitian (Sunardi \& Hendarsah, 2019: 19) yang menyatakan NPM tidak berpengaruh terhadap PBV. Berdasarkan penjelasan tersebut maka $\mathrm{Ha}_{3}$ ditolak.

$\mathrm{Ha}_{4}$ : Solvabilitas memiliki pengaruh terhadap Nilai Perusahaan

Berdasarkan hasil output persamaan sub struktural 2, diperoleh t hitung $-0.322 \mathrm{Sig}$. $0.750>0.05$. DAR tidak mempunyai pengaruh yang signifikan kepada PBV. Semakin banyaknya aktiva yang dimiliki oleh perusahaan dengan memakai pembiayaan hutang tidak dapat menaikkan nilai perusahaan. Karena secara hitungan matematis tingginya DAR bisa berdampak buruk bagi keuangan perusahaan karena menumpuknya hutang yang dimiliki perusahaan. Dan juga mengindikasikan investor belum memperhatikan nilai DAR dalam pengambilan keputusan investasi. Hal ini relevan dengan Ogolmagai (2013: 88) yang mengatakan DAR tidak mempunyai pengaruh terhadap Nilai Perusahaan sehingga $\mathrm{Ha}_{4}$ ditolak.

$\mathrm{Ha}_{5}$ : Harga Saham memiliki pengaruh terhadap Nilai Perusahaan

Output persamaan sub struktural 2 menunjukkan t hitung 3.390 Sig. $0.002<0.05$. Maka Harga Saham berpengaruh signifikan kepada PBV. Hal ini menjelaskan secara umum investor memantau perkembangan harga saham di bursa karena dengan meningkatkan harga saham mengindikasikan baiknya kinerja keuangan perusahaan yang nantinya dapat menaikkan nilai perusahaan tersebut. Informasi ini sesuai penelitian Nur'aidawati (2018: 81) bahwa apabila harga saham naik dapat menaikkan nilai perusahaan. Dari penjelasan di atas, maka $\mathrm{Ha}_{5}$ diterima.

$\mathrm{Ha}_{6}$ : Harga Saham mampu memediasi pengaruh Profitabilitas terhadap Nilai Perusahaan

Pengaruh langsung yang diberikan variabel NPM terhadap variabel PBV yaitu 0.186, dan pengaruh tidak langsung variabel NPM terhadap variabel PBV dimediasi Harga Saham yaitu : $0.253 \times 0.544=0.138$. Sehingga hasil total pengaruh NPM terhadap $\mathrm{PBV}=$ pengaruh langsung + pengaruh tidak langsung $=0.186+0.138=0.324$. Pengaruh langsung $>$ pengaruh tidak langsung. Memperlihatkan Harga Saham tidak mampu memediasi pengaruh NPM terhadap PBV. Berdasarkan penjelasan tersebut $\mathrm{Ha}_{6}$ ditolak.

$\mathrm{Ha}_{7}$ : Harga Saham mampu memediasi pengaruh Solvabilitas terhadap Nilai Perusahaan Pengaruh langsung yang diberikan variabel DAR terhadap variabel PBV yaitu 0.075 , dan pengaruh tidak langsung variabel DAR terhadap variabel PBV dimediasi Harga Saham yaitu : $0.202 \times 0.544=0.109$. Pengaruh tidak langsung $>$ pengaruh langsung. 
Menunjukkan Harga Saham mampu memediasi pengaruh DAR terhadap PBV. Berdasarkan penjelasan tersebut $\mathrm{Ha}_{7}$ diterima.

\section{E.KESIMPULAN}

Berdasarkan penelitian menggunakan cara analisis jalur (path analysis) dapat disimpulkan yakni: 1) Profitabilitas tidak berpengaruh signifikan terhadap Harga Saham, 2) Solvabilitas tidak berpengaruh signifikan terhadap Harga Saham, 3) Profitabilitas tidak berpengaruh signifikan terhadap Nilai Perusahaan, 4) Solvabilitas tidak mempunyai pengaruh signifikan terhadap Nilai Perusahaan, 5) Harga Saham mempunyai pengaruh signifikan terhadap Nilai Perusahaan, 6) Harga Saham tidak mampu memediasi Profitabilitas terhadap Nilai Perusahaan, dan 7) Harga Saham mampu memediasi Solvabilitas terhadap Nilai Perusahaan.

\section{SARAN}

1. Perusahaan terus meningkatkan laba bersih yang diperoleh terhadap total penjualan. Penjualan pada perusahaan farmasi terkadang dipengaruhi kondisi di luar perusahaan seperti kondisi ekonomi dan kesehatan global. Justru dengan banyaknya permintaan akan produk-produk kesehatan menjadikan penjualan meningkat. Serta perusahaan mengurangi pembelian aset dengan pembiayaan utang dikarenakan tingginya perolehan aset dengan cara utang akan mempengaruhi kondisi keuangan perusahaan dan dapat menurunkan nilai perusahaan.

2. Investor sebaiknya memperhatikan pergerakan harga saham perusahaan farmasi karena perubahan harga saham selama 5 tahun terakhir cenderung fluktuatif walaupun tahun terakhir cenderung naik agar investor mendapatkan imbal balik yang maksimum. Harga saham perusahaan farmasi yang semakin meningkatkan mengindikasikan kinerja manajemen semakin baik. Sehingga invetor diharapkan untuk terus memantau harga saham di pasar modal.

\section{DAFTAR PUSTAKA}

Ananda, N. A. (2017). Pengaruh Profitabilitas \& Struktur Modal Terhadap Nilai Perusahaan. Jurnal Ekonomi Dan Bisnis Indonesia, 2(1). https://doi.org/10.37673/jebi.v2i1.50

Abdul Kadim, K., \& Nardi, S. (2018). Eviews Analysis: Determinant Of Leverage And Company's Performance. Global and Stochastic Analysis (GSA), 5(7), 249-260.

Hovakimian, A., Opler, T., \& Titman, S. (2001). The debt-equity choice. Journal of Financial and Quantitative Analysis, 36(1), 1-24. https://doi.org/https://doi.org/10.2307/2676195

Hakim, L., Sunardi, N. (2017). Determinant of leverage and it's implication on company value of real estate and property sector listing in IDX period of 2011-2015. Man in India, 97(24), pp. 131-148.

Husaini, A. (2012). Pengaruh Variabel Return On Assets, Return On Equity, Net Profit Margin \& Earning Per Share Terhadap Harga Saham Perusahaan. Profit: Jurnal Administrasi Bisnis, 6(1).

Husain, T., \& Sunardi, N. (2020). Firm's Value Prediction Based on Profitability Ratios and Dividend Policy. Finance \& Economics Review, 2(2), 13-26.

Kadim, A., Sunardi, N \& Husain, T. (2020). The modeling firm's value based on financial ratios, intellectual capital and dividend policy.Accounting, 6(5), 859-870.

Manoppo, V. C. O., Tewal, B., \& Jan, A. B. H. (2017). Pengaruh Current Ratio, DER, ROA \& NPM Terhadap Harga Saham Pada Perusahaan Food and Beverages Yang 
Terdaftar Di Bei (Periode 2013-2015). Jurnal Riset Ekonomi, Manajemen, Bisnis Dan Akuntansi, 5(2). https://doi.org/10.35794/emba.v5i2.16399

Mentari, R. I. (2015). Dampak ROE, NPM, CSR, \& Ukuran Perusahaan terhadap harga saham perusahaan yang tercantum dalam indeks LQ45 BEI Periode 2010-2012.

Nardi Sunardi Et Al (2020). Determinants of Debt Policy and Company's Performance, International Journal of Economics and Business Administration Volume VIII Issue 4, 204-213

Nur'aidawati, S. (2018). Pengaruh Current Ratio (CR), Total Asset Turnover (TATO), Debt to Equity Ratio (DER) dan Return On Asset (ROA) Terhadap Harga Saham dan Dampaknya Pada Nilai Perusahaan (Studi Kasus Pada Sepuluh Bank Terbesar Yang Terdaftar di Bursa Efek Indonesia Periode. Jurnal Sekuritas (Saham, Ekonomi, Keuangan Dan Investasi), 1(3).

Ogolmagai, N. (2013). Leverage Pengaruhnya terhadap Nilai Perusahaan Pada Industri Manufaktur yang Go Public di Indonesia. Jurnal EMBA: Jurnal Riset Ekonomi, Manajemen, Bisnis Dan Akuntansi, 1(3).

Pamungkas, A. S., \& Maryati, S. (2017). Pengaruh Enterprise Risk Management Disclosure, Intellectual Capital Disclosure \& Debt to Aset Ratio terhadap Nilai Perusahaan. Prosiding Seminar Nasional Darmajaya, 1(1), 412-428.

Ponggohong, J. O. Y. (2016). Pengaruh Kinerja Keuangan Terhadap Harga Saham (Studi Pada Perusahaan Ritel Yang Terdaftar di BEI Tahun 2010-2013). Jurnal Berkala IImiah Efisiensi, 16(1).

Prasetyorini, B. F. (2013). Pengaruh ukuran perusahaan, leverage, price earning ratio dan profitabilitas terhadap nilai perusahaan. Jurnal IImu Manajemen (JIM), 1(1).

Rahayu, M., \& Sari, B. (2018). Faktor-faktor yang mempengaruhi nilai perusahaan. IKRAITH HUMANIORA: Jurnal Sosial Dan Humaniora, 2(1), 69-76.

Rinati, I. (2012). Pengaruh Net Profit Margin (NPM), Return On Assets (ROA) dan Return On Equity (ROE) terhadap harga saham pada perusahaan yang tercantum dalam indeks LQ45.

Rudangga, I. G. N. G., \& Sudiarta, G. M. (2016). Pengaruh Ukuran Perusahaan, Leverage, \& Profitabilitas terhadap Nilai Perusahaan. E-Jurnal Manajemen Universitas Udayana, 5(7).

Saputra, J., \& Martha, L. (2019). Analisis Kinerja Keuangan dan Nilai Perusahaan, Serta Pengaruhnya Terhadap Harga Saham.

Sia, V. L. R., \& Tjun, L. T. (2011). Pengaruh Current Ratio, Earnings per Share, \& Price Earning Ratio terhadap Harga Saham. Jurnal Akuntansi, 3(2), 136-158.

Sunardi, N. (2019). Profitabilitas, Likuiditas, Dan Multiplier Equity Pengaruhnya Terhadap Harga Serta Return Saham Pada Industri Manufaktur Tahun 20122017. Inovasi, 6(1), 58-73.

Sunardi, N., \& Febrianti, F. (2020). Likuiditas dan Kebijakan Hutang Pengaruhnya terhadap Kinerja Perusahaan dan Dampaknya Terhadap Nilai Perusahaan pada Industri Sektor Telekomunikasi di Indonesia. JIMF (Jurnal IImiah Manajemen Forkamma), 3(3).

Sunardi, N., \& Hendarsah, D. (2019). Faktor-Faktor yang Mempengaruhi Laba dan Dampaknya pada Nilai Perusahaan (Studi Kasus Pada Perusahaan BUMN Bidang Kontruksi Yang Terdaftar Di Bursa Efek Indonesia tahun 2008-2017). Jurnal SEKURITAS (Saham, Ekonomi, Keuangan Dan Investasi), 3(1), 1-21. 